\section{A convenient device for xeno- biotic dosing and haemolymph sampling in Carcinus maenas (Portunidae, Decapoda)}

\author{
A. Robert, B. Rocher, F. Nihoul, \\ T. Monsinjon, F. Le Foll, T. Knigge \\ UMR-I 02 INERIS-URCA-ULH Unité \\ Stress Environnementaux et \\ Biosurveillance des milieux aquatiques \\ (SEBIO), Le Havre University, France
}

\section{Introduction}

The shore crab or European green crab, Carcinus maenas (L. 1758), is one of the most widely studied crustaceans in the world and considered a valuable model for ecotoxicological research. ${ }^{1,2}$ Consequently, it has been used to assess the impact of metals, ${ }^{3}$ pesticides, ${ }^{4}$ xenostrogens ${ }^{5}$ and drugs. ${ }^{6}$ Naturally, shore crabs display a high tolerance to fluctuations of abiotic factors in their environment, which may entail hypoxia, salinity changes or temperature stress (heat-shock and/or cold shock, respectively). They also resist considerably to anthropogenic pollution of the aquatic environment deriving from urban, industrial, agricultural and marine activities. The xenobiotic compounds released in the aquatic environment may either remain dissolved in the water column or accumulate in the sediments from which they can become resuspended and subsequently expose crabs through feeding and water column. As the shore crab occupies a strategic position within the marine food chain, $C$. maenas is also an important vector of contamination.

Generally, three different types of exposures are performed when $C$. maenas is employed as an experimental test organism: i) animals may be exposed to contaminants dissolved in the water body; ${ }^{7}$ ii) chemical substances may be administrated via food; or iii) a substance may be introduced into the animal's body by in vivo injection. ${ }^{8}$ Accordingly, the amount of any substance to which the animals are exposed may vary and differ considerably from the nominal concentration. Although water or food exposures are environmentally more realistic scenarios, the best control of the dose that effectively enters the animal's body is obtained with the injection procedure. In decapod crustaceans, in vivo injections are usually performed through the arthrodial membrane at the base of the fourth walking leg with a syringe. A drawback of this treatment is that the crabs experience handling stress including short-term exposure to atmospheric air with subsequent reemersion. This may affect the physiological parameters that are going to be measured following exposure to a test-substance. Also, the injection as well as the sampling of haemolymph bears the risk of triggering leg autotomy. Those drawbacks lead us to develop a new method of injection and haemolymph sampling in order to reduce stress factors, which may affect the physiological responses of the crabs to xenobiotic exposure. Here we describe a system that allows convenient and quick injection and sampling of haemolymph without any air exposure.

\section{Materials and Methods}

Individuals of $C$. maenas were collected at a subtidal sampling site at Roscoff Biological Station, Roscoff, France, located on the northern coast of Brittany. Male intermoult crabs with $65 \pm 5.5 \mathrm{~mm}$ carapace width were selected for experimentation. After transfer to the laboratory, animals were placed in filtered and aerated seawater of $35 \pm 2 \mathrm{mS}$ conductivity at a temperature of $9^{\circ} \mathrm{C}$. The climate chambers were maintained on a $12 \mathrm{~h}$ light-dark cycle (07:00 a.m.-07:00 p.m.). Shore crabs were fed with mussels, Mytilus edulis, collected at Yport, France, every second day. The crabs were allowed to acclimate to these conditions for seven days, after which the injection/sampling device (see below) was placed. Crabs were acclimated to this device for another seven days before the onset of experiments.

Animals were used for experimentation $48 \mathrm{~h}$ after the last feeding in order to stabilize glycaemia as the haemolymph glucose level served as a proxy for a stress response. This stress related hyperglycemia is supposed to be mediated through the crustacean hyperglycemic hormone. ${ }^{9}$ Crabs were kept throughout the administration of a model chemical compound and haemolymph sampling inside a pierced plastic container with saline water at a height just about to cover the carapace sufficiently so as to maintain the animals submersed in water, but to be able to conduct injections and samplings from above the water surface. This procedure was compared to conventional injection and sampling via the arthrodial membrane of the fourth paraeopod, with injection at the right and sampling at the left paraeopod, at otherwise identical conditions. For this method it was, however, necessary to take the crabs out of water after which they were replaced into their container.

The injection device consists of a plastic cone made of ordinary $200 \mu \mathrm{L}$ and $1000 \mu \mathrm{L}$ pipette tips. The $200 \mu \mathrm{L}$ tips of $50 \mathrm{~mm}$ length are cut into four pieces of 10 to $15 \mathrm{~mm}$ length and mounted with each part forced into the other (Figure 1A). An external supporting ring is cut out of a $1000 \mu \mathrm{L}$ pipette (Figure 1B).
Correspondence: Alexandrine Robert, Unité Stress Environnementaux et BIOsurveillance des milieux aquatiques (SEBIO) Université du Havre, UFR Sciences \& Techniques, 25 rue Philippe Lebon, Bat. ST2, 76063 Le Havre, France. E-mail: alexandrine.robert@univ-lehavre.fr

Key words: injection device, sampling, hemolymph, glycaemia, crab.

Acknowledgements: this work was financed by the EU Interreg IVA programme Peptide Research Network of Excellence (PeReNE).

Conference presentation: ECOBIM meeting, 2014 May, Brest, France.

This work is licensed under a Creative Commons Attribution NonCommercial 3.0 License (CC BYNC 3.0).

(C) Copyright A. Robert et al., 2014

Licensee PAGEPress, Italy

Journal of Xenobiotics 2014; 4:4903

doi:10.4081/xeno.2014.4903

This element is indispensable to maintain the cone onto the carapace of the crab. To fix the injection device, crabs are placed on ice for 5 min in order to anesthetize them and a hole of $0.8 \mathrm{~mm}$ in diameter is drilled into the carapace above the pericardial sinus. Subsequently, the injection device is inserted into the hole and glued to the dry carapace by epoxy (Sader, France), which is hardened for at least one hour before the animals can be returned into the water. For the injection of the test substance and the sampling of haemolymph, a polypropylene $1 \mathrm{~mL}$ syringe (Dutscher, France) with a G25 5/8 needle $(0.5 \mathrm{~mm}$ in diameter and $16 \mathrm{~mm}$ in length) is inserted into the cone, whilst keeping crabs submerged.

Two different experiments were carried out in order to assess i) the distribution efficiency of the injection device as compared to the conventional method; and ii) the stress level caused by hemolymph sampling through the injection device as well as through the arthrodial membrane of the fourth paraeopod. In the first experiment $50 \mu \mathrm{L}$ indigotine color (E132) was injected either through the injection device or via the right fourth paraeopod. The distribution of the colorant was traced by collecting $50 \mu \mathrm{L}$ of hemolymph from the left fourth paraeopod for both means of injection at $5 \mathrm{~min}, 10 \mathrm{~min}, 15 \mathrm{~min}, 30 \mathrm{~min}, 45 \mathrm{~min}, 60$ min, 90 min and 120 min after injection and spectrophotometric reading at $608 \mathrm{~nm}$ (Libra S22, Biochrome, UK). In the second experiment the blood glucose level was followed over a $12 \mathrm{~h}$ day period by sampling $100 \mu \mathrm{L}$ haemolymph every $2 \mathrm{~h}$ via the injection device or via the conventional sampling at the right fourth paraeopod. Haemolymph was snapfrozen without anticoagulant and stored at $20^{\circ} \mathrm{C}$ until further processing. The glucose 
content was determined using a glucose assay kit (Biochain, USA), which was adapted for use with crustacean haemolymph. Briefly, 25 $\mu \mathrm{L}$ haemolymph was mixed with $200 \mu \mathrm{L}$ of 0 toluidine, then heated at $95^{\circ} \mathrm{C}$ for $8 \mathrm{~min}$ and cooled at $4^{\circ} \mathrm{C}$ for at least $4 \mathrm{~min}$. Samples were then transferred to a 96 well plate (Nunc, France) and the colorimetric reaction was read (Infinite M200, Tecan, Switzerland) at $630 \mathrm{~nm}$. A standard curve ranging from 0 to $37.5 \mathrm{mg} / \mathrm{dL}$ was obtained with glucose standard (Biochain, USA).

\section{Results and Discussion}

The relative intensity of haemolymph coloration over a two hours time-course is presented in Figure 2. For the conventional injection procedure via the paraeopod, hemolymph coloration increased over the first 15 min after injection, with no coloration detected at $5 \mathrm{~min}$ and about half of the maximal coloration reached after $10 \mathrm{~min}$. From $15 \mathrm{~min}$ onwards coloration remained steady until about $90 \mathrm{~min}$, followed by a slight decrease towards the end of the experiment. The results obtained by using the injection device essentially showed a similar pattern, but a considerably more rapid distribution of the colorant could be noted as $40 \%$ coloration was reached already at $5 \mathrm{~min}$. The trend towards a lesser coloration at the end of the experiment also became visible. However, the values display a somewhat higher variability than those obtained for injection through the paraepod. This, most likely, is due to methodological or biological variation rather than to the method itself. Notably, after $45 \mathrm{~min}$ the haemolymph became increasingly turbid, a phenomenon that might have affected the spectrophotometric measurements. In summary, both injections methods appear to assure substance distribution throughout the animal's body in an efficient manner, however, with the injection device allowing for a faster circulation of the test substance. This can become important, in particular, for investigating rapid responses to a contaminant.

The course of the haemolymph glucose level in crabs over a period of $12 \mathrm{~h}$ is shown in Figure 3. Despite obvious individual variation in glucose levels, conventional injection resulted in quite noisy pattern of glucose levels with apparent up- and down-regulations of glycaemia (Figure 3A) translating into increased glucose levels at the two first samplings and oscillating around the initial level at $\mathrm{t}=0$ (arbitrarily set at 1 ; Figure 3B). The initial increase in glycaemia was also observed for $C$. maenas when exposed for $2 \mathrm{~h}$ to air. $^{10}$ On the contrary, sampling of haemolymph through the injection device exhibited much more stable glucose levels, albeit at different levels for the different individuals (Figure 3C). If compared to the level at the beginning of the experiment $(\mathrm{t}=0)$, only minimal changes can be observed (Figure 3D). Also, the individual variability was rather marginal. We therefore hypothesize that the considerably higher variation ( $>200 \%$, with a coefficient of variation of $30 \%$ ) obtained with injections through the arthrodial membrane of the paraeopod are due to handling stress to which the animal responds by mobilizing glucose. On the other hand, sampling through the injection device leads to minimal stress of the animal resulting in glycogenic homeostasis. Notably, by using the injection device crabs remain submerged, which eliminates air stress on animals, this being a means of avoiding confounding factors when measuring the effect of a xenobiotic. It should also be noted that, in contrary to results reported in the literature, glycaemia was devoid of any endogenous rhythm, at least during the day, as has been demonstrated for some decapod crus-

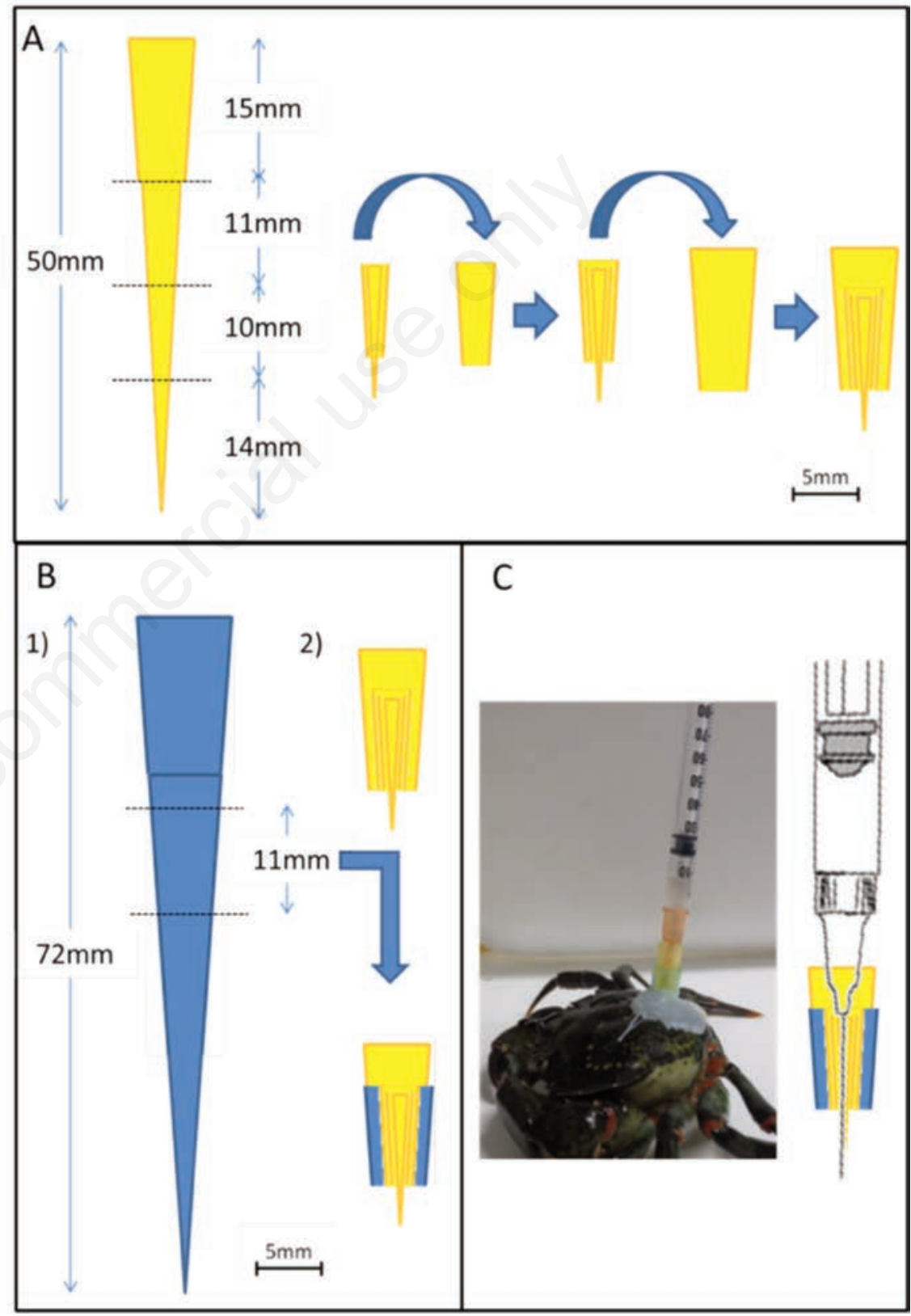

Figure 1. Injection device: graphical depiction of fabrication using $200 \mu \mathrm{L}$ and $1000 \mu \mathrm{L}$ pipette tips. A) Cutting and assembly of parts derived from the $200 \mu \mathrm{L}$ tips. B) 1 . Withdrawal of an $11 \mathrm{~mm}$ middle section from a $1000 \mu \mathrm{L}$ tip and 2. completion of the injection device. C) Shore crab equipped with injection device fixed with epoxy on his carapace and schematic representation of the inserted syringe. 

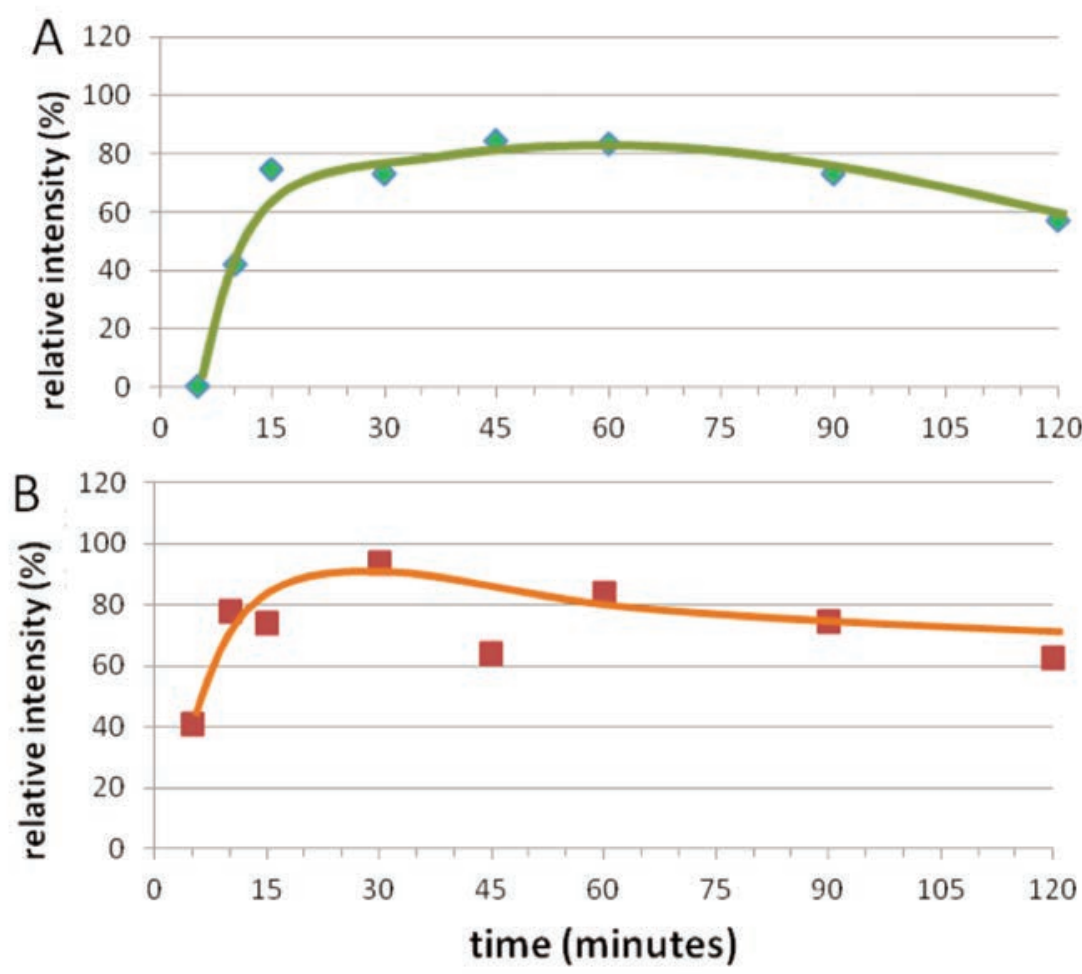

Figure 2. Relative intensity of indigotine color (E132) in crab haemolymph. A) Lateral injection $(t=0)$ and contra-lateral sampling through the right and the left fourth paraeopod, respectively. B) Dorsal injection through the injection device $(t=0)$ and lateral sampling at the left fourth paraeopod.
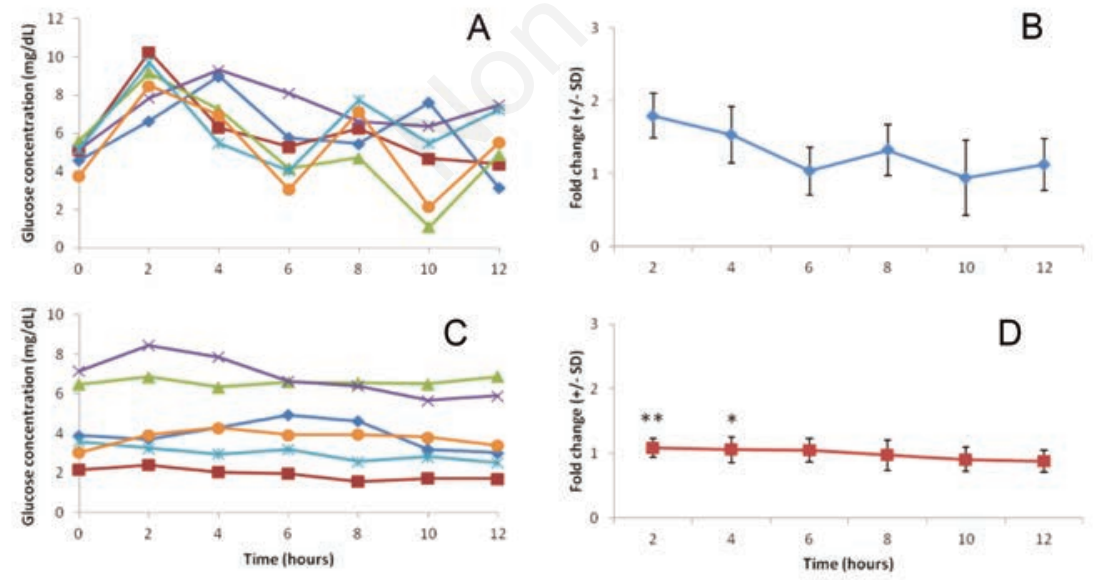

Figure 3. Variations of haemolymph glucose in crabs over a 12 h light cycle. A) Glucose levels of individual crabs after sampling via the fourth paraeopod; B) fold change in glycaemia after sampling via the fourth paraeopod $(n=6)$, means $\pm S D ; C)$ glucose levels of individual crabs after sampling via the injection device; $D$ ) fold change in glycaemia after sampling via the injection device $(n=6)$, means $\pm S D$. Significance compared with control determined by $\mathrm{t}$-test ${ }^{*} \mathrm{P}<0.05,{ }^{* *} \mathrm{P}<0.01$. taceans. ${ }^{11,12}$ This, most likely, is an effect of the acclimation to the experimental conditions including the injection device. It is understood that this method of dosing contaminants and reducing the influence of some important confounding factors represents a highly artificial system. The effects that may be observed using the injection device are likely to be less influenced by secondary parameters, but at some point they will have to be validated by moving towards more environmentally realistic exposures.

\section{Conclusions}

The present study demonstrates that the injection device is a suitable method for in vivo injection in ecotoxicological studies using crabs and other decapod crustaceans. Its significant advantage is that it allows for precise dosage of the compound of interest and that it largely reduces handling stress, which may confound the effects induced by the compound to be tested. It therefore represents an essential prerequisite to assess reliable effects. Furthermore, the substance injected through the injection device has a rapid diffusion rate, which potentially permits to investigate early responses. Eventually, the injection device is a convenient means, which greatly facilitates sampling of haemolymph at frequent intervals.

\section{References}

1. Leignel V, Stillman JH, Baringou S, Thabet R, Metais I. Overview on the European green crab Carcinus spp. (Portunidae, Decapoda), one of the most famous marine invaders and ecotoxicological models. A review. Environ Sci Pollut Res Int 2014 [In press].

2. Rodrigues ET, Pardal MA. The crab Carcinus maenas as a suitable experimental model in ecotoxicology. Environ Int 2014;70:158-82.

3. Ben-Khedher S, Jebali J, Houas Z, Naweli H, Jrad A, Bousseta H. Metals bioaccumulation and histopathological biomarkers in Carcinus maenas crab from Bizerta lagoon, Tunisia. Environ Sci Pollut Res 2014;21:4343-57.

4. Rodrigues AP, Gravato C, Guimaraes L. Involvement of the antioxidant system in differential sensitivity of Carcinus maenas to fenitrothion exposure. Environ Sci Process Impacts 2013;15:1938-48.

5. Ricciardi F, Matozzo V, Marin MG. Effects of 4-nonylphenol exposure in mussels (Mytilus galloprovincialis) and crabs (Carcinus aestuarii) with particular 
emphasis on vitellogenin induction. Mar Pollut Bull 2008;57:365-72.

6. Mesquita SR, Guilhermino L, Guimarães L. Biochemical and locomotor responses of Carcinus maenas exposed to the serotonin reuptake inhibitor fluoxetine. Chemosphere 2011;85:967-76.

7. Rodrigues AP, Lehtonen KK, Guilhermino L, Guimarães L. Exposure of Carcinus maenas to waterborne fluoranthene: Accumulation and multibiomarker responses. Sci Total Environ 2013;443:454-63.

8. Santos EA, Keller R, Rodriguez E, Lopez L.
Effects of serotonin and fluoxetine on blood glucose regulation in two decapod species. Braz J Med Biol Res 2001;34:75-80.

9. Chung JS, Webster SG. Dynamics of in vivo release of molt-inhibiting hormone and crustacean hyperglycemic hormone in the shore crab, Carcinus maenas. Endocrinology 2005;146:5545-51.

10. Santos EA, Keller R. Effect of exposure to atmospheric air on blood glucose and lactate concentrations in two crustacean species: a role of the Crustacean hyperglycemic hormone (CHH). Comparat
Biochem Physiol Part A Physiol 1993;106:343-47.

11. Sathyanandam S, Vasudevan S, Natesan M. Serotonin modulation of hemolymph glucose and crustacean hyperglycemic hormone titers in Fenneropenaeus indicus. Aquaculture 2008;281:106-12.

12. Sreenivasula Reddy P, Pushpalatha T. Effect of serotonin on hemolymph glucose regulation in the fresh water edible crab Oziotelphusa senex senex. Aquaculture 2007;266:274-8. 